\title{
Fabrication and characterization of a coplanar nickel- metal hydride microbattery equipped with a gel electrolyte
}

\author{
Ali Khazaeli, Dominik P.J. Barz* \\ Department of Chemical Engineering, Queen's University, Kingston, ON, KrL 3N6, \\ Canada
}

\begin{abstract}
The growing utilization of portable and autonomous micro devices results in a need for novel integrated power supplies with low power densities and energy contents. We report on a rechargeable thin-film microbattery which is manufactured using typical microfabrication methods. In detail, the microbattery is based on the nickel-metal hydride chemistry and fabricated with a coplanar design on a glass wafer. Ionic conductivity is enabled with a gel electrolyte that is sealed with a polymer to prevent dessication. We compare the electrode characteristics in the gel electrolyte and in a corresponding liquid electrolyte. Charge-discharge measurements at different currents are performed to evaluate the performance of the microbattery. The capacity is found to be $2.8 \mu \mathrm{Ah} \mathrm{cm}^{-2} \mu \mathrm{m}^{-1}$ at a current density of $1 \mathrm{~mA} \mathrm{~cm}{ }^{-2}$. We also investigate the microbattery degradation over the number of chargedischarge cycles using electrochemical impedance spectroscopy. The results reveal that the capacity after 100 cycles decreases to around half of the initial
\end{abstract}

\footnotetext{
*Corresponding Author

$U R L$ : dominik. barz@queensu.ca (Dominik P.J. Barz )
} 
value which is mainly attributed to the gel electrolyte degradation.

Keywords: Thin-film battery, Nickel-metal hydride battery, Gel

electrolyte, Microfabrication, Cyclic Voltammetry

\section{Introduction}

The practical application of portable and wearable autonomous micro devices is linked to the development of low-power supplies which can be directly integrated during the production process [1]. Technologies which can benefit from such on-board power sources include various micro-electro-mechanicalsystems (MEMS) such as personalized health-care (both wearable and implantable) devices [2], autonomous sensor networks [3] and radio-frequency identification devices [4].

A brief literature review from the last two decades shows the progress in reducing energy consumption. About 20 years ago, power requirements for standby and data collection/processing of remote sensing microsystems were assumed to be in the range of 3 to $30 \mu \mathrm{W}$ and 100 to $1000 \mu \mathrm{W}$, respectively [5]. A typical example is the flexible temperature and motion sensing device with a power consumption of $35 \mu \mathrm{W}$ reported in Ref. [6]. In terms of biomedical applications, Chandrakasan et al. gave power requirements of less than $10 \mu \mathrm{W}$ for pacemakers and cardioverter-defibrillators, $140 \mu \mathrm{W}$ for a body-area monitoring microsystem, and a power range of 100 to $2000 \mu \mathrm{W}$ for hearing aids [7].

The recent progress of MEMS technology lowered these demands and enabled monitoring systems for body temperature/activity with ultra-low power consumption. A typical example is the wireless sensor node devel- 
oped by Okada et al. which requires less than $500 \mathrm{nW}$ [8]. Other works on ultra-low power systems included a wireless sensor node to monitor animal health which requires $460 \mathrm{nW}$ [9] and a temperature compensated timer for wireless sensor nodes which needs only $660 \mathrm{pW}$ [10] in order to operate. Nevertheless, general statements about the power consumption of micro devices are difficult since they depend on the task and system complexity; i.e., the design and number of sensors, actuators and processors which form the microsystem. All things considered, we note that the required power spans over several orders of magnitude and the range is estimated to be roughly $0.1 \mu \mathrm{W}$ to $1000 \mu W$.

Capacity requirements of miniaturized systems are hardly discussed in literature and depend on the operation regime. Many sensing tasks do not require continuous but rather intermittent collection of measurement data and, therefore, less capacity is needed for a given operation time. For example, if we assume that the wireless sensor node reported by Okada et al. $[8,9]$ performs its measurement every minute for a duration of 10 seconds, the accumulated operation time is only around $4 \mathrm{hr} /$ day. This requires a daily capacity of less than $1.5 \mu \mathrm{Ah}$, and assuming a nominal voltage of 1.2 $\mathrm{V}$, its energy consumption is less than $2 \mu \mathrm{Wh} /$ day.

There is another important consequence of the electrical characteristics since the microsystem size is often determined by the size of the power supply [11]. In other words, the advantages which are achieved through miniaturization are compromised when conventional (and over-sized) power sources, such 
as button cells, are used. Furthermore, the utilization of conventional power sources in microsystems can have other drawbacks such as connection problems, unwanted electronic interactions and difficulties to control the power delivered. Consequently, the supply of electric power is a barrier to further development and application of MEMS technology due to the poor performances, masses (or volumes), and lifetimes of current power sources [12].

Several microbatteries for application in microsystems have been reported. Many of them are based on lithium due to the high energy content $[13,14]$. However, they require an electronic circuit to maintain a certain potential range in order to avoid thermal runaway and feature high variations in the cell potential if over(dis-)charged [3]. Additionally, cell encapsulation is critical due to the high lithium reactivity when it is exposed to moisture which all leads to increased complexity with respect to integration.

If the demand of capacity and power are only moderate, cells other than lithium are promising. Zinc (Zn) electrodes are attractive in terms of cost and simplicity of fabrication. However, dendrite formation and shape change after several charge-discharge cycles constitutes a technical challenge for rechargeable Zn-based batteries which can be somewhat mitigated by using a gel electrolyte $[15,16]$. Despite these challenges, different Zn-based primary and secondary microbatteries were realized. Lee et al. investigated a zinc-gold primary battery with a nominal cell potential of $1.5 \mathrm{~V}$ and an alkaline electrolyte [17]; the capacity was around $4.88 \mathrm{mAh} \mathrm{cm}^{-2}$. In order to increase the power density of a zinc-nickel microbattery, Chamran et al. introduced 
a three-dimensional (3D) design with high aspect ratio posts [18]. A 3D primary zinc-air microbattery with a micromachined metallic scaffold, having

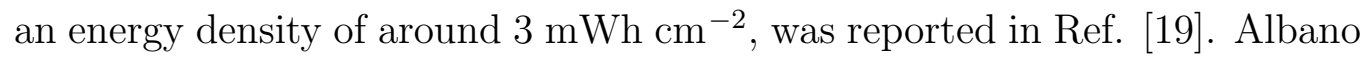
et al. fabricated an integrated primary zinc-silver oxide microbattery with a capacity of $140 \mu \mathrm{Ah} \mathrm{cm}^{-2}$ for the use in implantable MEMS devices [20]. A 2D and a 3D zinc-silver microbattery fabricated with inkjet printing and a respective energy content of 2.3 and $3.9 \mathrm{mWh} \mathrm{cm}^{-2}$ was reported in Refs. $[21,22]$.

Nickel-metal hydride (Ni-MH) cells do not provide as high energy densities as lithium-based cells either, but we conclude from our brief literature review that they may be applied for microsystems with low and ultra-low power requirements. Additionally, these batteries do not suffer from electrode shape change and do not require encapsulation to protect them from moisture; therefore, we consider them as viable candidates for powering MEMS. To the best of our knowledge, no attempts were made to build a Ni-MH microbattery but that of Do et al., who screen-printed thick-film electrodes on a porous ceramic substrate $[23,24]$. Here, the question arises whether such methods and materials can be part of regular microfabrication process.

The main motivation of our work is to create a Ni-MH thin-film battery which can be easily integrated into microsystems. Hence, the process that we develop is comprised of common microfabrication methods and substrates. Conventional Ni-MH batteries feature liquid alkaline electrolytes which show good performance due to their high conductivity but can cause a leakage problem. This can be significantly alleviated using a non-liquid electrolyte 
$[25,26]$; thus, we employ an alkaline gel. This article proceeds with the section on materials and experimental methods. Then, the microbattery design and fabrication is discussed and the microbattery is characterized using different electrochemical methods. Finally, the article is summarized with some concluding remarks.

\section{Materials and Experimental Methods}

In this section, we introduce the materials, instruments, and characterization techniques that are used for this work.

\subsection{Materials}

Glass wafers (Globe Scientific Inc., Paramus, NJ, USA) with an area of $2.54 \times 7.62 \mathrm{~cm}^{2}$ are used as a substrate for the microfabrication of the battery. Each wafer provides sufficient area for the fabrication of at least eight microbatteries. Gold (Au) and chromium (Cr) pellets (Kurt J. Lesker Canada, Inc., Concord, ON, Canada) with purities of $99.995 \%$ and $99.998 \%$ are used for the physical vapor deposition of the current collectors. The intermetallic alloy which becomes the MH electrode is sputtered from a custom-made target (Kurt J. Lesker Canada Inc., Concord, ON, Canada). The manufacturer reports the target specifications: elemental alloy composition of $\mathrm{LaNi}_{4.7} \mathrm{Al}_{0.3}$ with a purity of $99.9 \%$, diameter of $7.62 \mathrm{~cm}$ and thickness of $0.317 \mathrm{~cm} \pm$ $0.025 \mathrm{~cm}$. The geometry of the electrodes on the wafer are defined using shadow masks made from Kapton ${ }^{\circledR}$ 18-1F-12 sheet (DuPont, Wilmington, DE, USA). Electrodeposition of nickel hydroxide $\left(\mathrm{Ni}(\mathrm{OH})_{2}\right)$ onto the current collectors is performed using a an aqueous solution of nickel nitrate hexahydrate $\left(\mathrm{Ni}\left(\mathrm{NO}_{3}\right)_{2} \cdot 6 \mathrm{H}_{2} \mathrm{O}\right)$ (puriss. p.a., >98\%, Sigma-Aldrich Canada, 
Oakville, ON, Canada). Materials required for the gel electrolyte preparation include acrylic acid $\left(\mathrm{C}_{3} \mathrm{H}_{4} \mathrm{O}_{2}\right)$, N, $\mathrm{N}^{\prime}$-methylene-bis(acrylamide) (MBA), potassium hydroxide $(\mathrm{KOH})$, and potassium persulfate $\left(\mathrm{K}_{2} \mathrm{~S}_{2} \mathrm{O}_{8}\right)$ which are all of reagent grade (> $98 \%$, Sigma-Aldrich Canada, Oakville, ON, Canada). Also, the heat-curable polymer (poly)dimethyl-siloxane (PDMS) (Sylgard 184, Dow Corning, USA) is used for the encapsulation of the gel electrolyte. Deionized (DI) water (RiOs-DI3 water purification system, EMD Milipore Corporation, MA, USA) with a conductivity of $<1 \mu \mathrm{S} / \mathrm{cm}$ is used throughout this work.

\subsection{Manufacturing instruments}

$\mathrm{Cr}$ and $\mathrm{Au}$ thin-films are deposited onto the glass wafer using an electron beam evaporator (Thermionics $3 \mathrm{~kW}$ Linear e-gun, Port Townsend, WA, USA) coupled with an IG4500 ion gauge controller. The deposition rate is controlled by a deposition crystal monitor (INFICON Inc., East Syracuse, NY, USA). A magnetron sputter deposition system (PVD 75, Kurt J. Lesker Co., Pittsburgh, PA, USA) is employed to grow the intermetallic films from the target. All film depositions are performed at the NanoFabrication Kingston Laboratory (NFK, Kingston, ON, Canada). In terms of the shadow masks, the Kapton sheets are cut using a picosecond laser micromachining system (A Series, Oxford Lasers, Inc, Shirley, MA, USA). The electrodeposition of the $\mathrm{Ni}(\mathrm{OH})_{2}$ thin-films and all electrochemical measurements are performed using a potentiostat/galvanostat (PGSTAT302N, Metrohm Autolab B.V., Utrecht, The Netherlands). The electrochemical setup used for

the electrodeposition consists of the working electrode compartment, a nickel mesh counter electrode, and a $\mathrm{Ag} / \mathrm{AgCl}(3 \mathrm{M} \mathrm{KCl})$ reference electrode. 


\subsection{Electrochemical characterization}

We perform various measurements at room temperature $(T=298 \mathrm{~K})$ to characterize gel electrolyte, single electrodes, as well as the combination as a microbattery.

$\underline{\text { Gel electrolyte characterization }}$

Electrochemical impedance spectroscopy (EIS) is employed to determine the ionic conductivity of the alkaline gel electrolyte. The gel is sandwiched between two stainless steel electrodes, each with an surface area of $0.5 \mathrm{~cm}^{2}$, and with a distance of $0.5 \mathrm{~cm}$ to each other. An excitation signal of $5 \mathrm{mV}$ is applied to the electrodes and the impedance spectrum is recorded in a frequency range of $1 \mathrm{MHz}$ to $100 \mathrm{mHz}$.

For practical applications, it is of interest to infer the influence of using the gel electrolyte on the microbattery performance. The gel electrolyte must have a sufficient electrochemical stability range and withstand the oxidation and reduction potentials that are present during battery operation. Additionally, we expect differences due to the lack of convection and the lower (pore) diffusivity in a gel. Therefore, we measure cyclic voltammograms (CVs) of a (polycrystalline) platinum (Pt) rod working electrode immersed in the gel electrolyte and compare them with those in a comparable aqueous $\mathrm{KOH}$ solution. We choose the Pt electrode as a test case since it shows distinct and well-understood characteristics in alkaline media such as the underpotential deposition of hydrogen [27]. The investigated potential window is $-1.2 \mathrm{~V}$ to $1 \mathrm{~V}$ vs. a $\mathrm{Ag} / \mathrm{AgCl}(3 \mathrm{M} \mathrm{KCl})$ reference electrode and the scan rate is 10 
$\mathrm{mVs}^{-1}$

To provide best possible contact between electrode and gel electrolyte, we pour un-polymerized electrolyte solution into the two compartment electrochemical setup which contains the Pt electrode, a glassy carbon counter electrode and the reference electrode. The polymerization takes place inside the cell and a transparent gel electrolyte is formed after $2 \mathrm{hr}$. Prior to any CV measurement in this work, a current-interrupt method is applied to measure the potential difference (IR-drop) between working and reference electrode. The average value for the IR-drop correction in the gel is $10.2 \Omega \pm 0.1 \Omega$. In case of the aqueous electrolyte, the reference electrode is inserted inside a Luggin capillary to minimize the IR-drop.

$\underline{\text { Single electrode and battery characterization }}$

The microfabricated electrodes are first characterized by measuring CVs in the alkaline gel electrolyte and, for the sake of comparison, in a corresponding aqueous $\mathrm{KOH}$ solution. Measurements are conducted in a similar way as described above. The microfabricated battery is characterized by measuring galvanostatic charge-discharge profiles that are recorded at a current density of $1 \mathrm{~mA} \mathrm{~cm}{ }^{-2}$. The polarization behavior is investigated by discharging the battery at different current densities ranging from $10 \mu \mathrm{A} \mathrm{cm} \mathrm{cm}^{-2}$ to 50 $\mathrm{mA} \mathrm{cm}^{-2}$. Finally, we employ EIS to infer the battery degradation over an increasing number of charge-discharge cycles. These measurements are performed at open circuit voltage (OCV) by superposition of an $\mathrm{AC}$ voltage of $5 \mathrm{mV}$ that is scanned over a frequency range of $100 \mathrm{kHz}$ to $10 \mathrm{mHz}$. 


\section{Results and discussion}

In this section, we first describe the design and fabrication process of the Ni-MH microbattery. Then, we present the results of the gel and single electrode characterization. We continue by giving insights into the charge and discharge behavior of the microbattery and the resulting degradation.

\subsection{Battery design}

Figure 1 gives an exploded view of the coplanar battery design consisting of two L-shaped current collectors, $\mathrm{MH}$ and Ni electrode, gel electrolyte and a PDMS cover which protects the gel from desiccation. The utilization of a gel electrolyte considerably alleviates the (potential) leaking problem related to the utilization of a liquid electrolyte. In fact, the required sealing of batteries with a liquid electrolyte increases the complexity of cell design and fabrication. In our design, only a simple PDMS film is used to protect the gel electrolyte from desiccation. Since the operating temperature of the microbattery is below $70{ }^{\circ} \mathrm{C}$, and the $\mathrm{KOH}$ concentration in the gel electrolyte is significantly less than 30 wt.\%, the etching of PDMS by the gel electrolyte is negligible $[28,29]$. In detail, the L-shape of the current collectors can be

divided into a rectangular pad of $10 \times 2 \mathrm{~mm}^{2}$ and a square-shaped pad of $5 \times 5 \mathrm{~mm}^{2}$. The square-shaped pad solely serves as electronic contact with the external circuit. The electrodes are deposited with a foot print of $5 \times 2$ $\mathrm{mm}^{2}$ on the L-shaped part of the current collectors. The distance between positive and negative electrode is $0.5 \mathrm{~mm}$. Both electrodes are in contact with the gel electrolyte which is encapsulated by a PDMS layer that features 
a $5 \times 5 \mathrm{~mm}^{2}$ square-shaped void space with a depth of approximately $1 \mathrm{~mm}$.

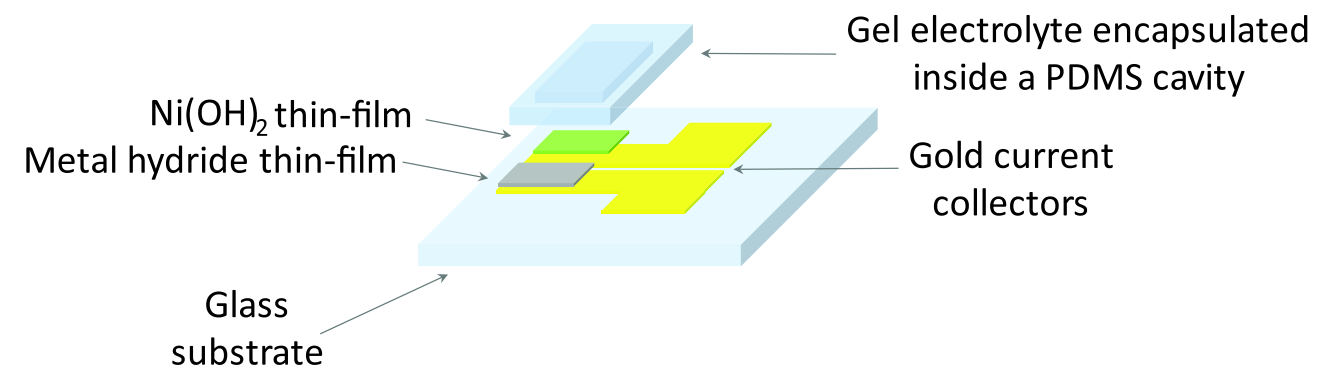

Figure 1: Exploded view of the microbattery design (dimensions are not to scale). The Cell employs a $\mathrm{NiOOH} / \mathrm{Ni}(\mathrm{OH})_{2}$ redox couple as positive electrode (green) and a sputtered intermetallic alloy (black) as a negative electrode. Both electrodes are deposited on gold current collectors (yellow). The gel electrolyte is encapsulated in the rectangular cavity of the PDMS film.

\subsection{Microfabrication}

We fabricate eight identical microbatteries on a glass wafer but subsequent testing is performed on single units. Fig. 2 shows a schematic of the fabrication process. All glass wafers are first pre-treated with a cleaning process involving acetone, isopropanol, and DI water. Then, the multi-layer films are grown using different sputtering processes; details of the operating conditions are listed in Table 1. The wafers are first transferred to the e-beam evaporation chamber and covered with a shadow mask to define the footprint of the current collectors. A $10 \mathrm{~nm}$ Cr film is sputtered which serves as a seed layer improving the adherence between current collector and glass substrate. Then, the Au current collectors are grown, with a thickness of $200 \mathrm{~nm}$, on top of the seed layers. In order to fabricate the $\mathrm{MH}$ electrodes, the wafer is transferred to the magnetron sputtering chamber. We use another shadow 
mask with the footprint of the electrodes to grow $1 \mu \mathrm{m}$ thick intermetallic alloy films on top of every second current collector. We fabricate films with a composition of $\mathrm{La}_{1.11} \mathrm{Ni}_{4.73} \mathrm{Al}_{0.19}$ as reported in detail in our previous work $[30]$.

Table 1: Sputtering parameters for the multi-layer deposition of the thin-film electrodes.

\begin{tabular}{lccc} 
Parameter & \multicolumn{3}{c}{ Value } \\
\hline Material & $\mathrm{Cr}$ & $\mathrm{Au}$ & $\mathrm{LaNi}_{4.7} \mathrm{Al}_{0.3}$ \\
\hline Sputtering method & E-beam & E-beam & Magnetron DC \\
Vacuum base pressure & $<10^{-6} \mathrm{~Pa}$ & $<10^{-6} \mathrm{~Pa}$ & $<10^{-6} \mathrm{~Pa}$ \\
Chamber pressure & $0.4 \mathrm{~Pa}$ & $0.4 \mathrm{~Pa}$ & $0.4 \mathrm{~Pa}$ \\
Sputtering power & $\mathrm{n} / \mathrm{a}$ & $\mathrm{n} / \mathrm{a}$ & $150 \mathrm{~W}$ \\
Plate Spin rate & $\mathrm{n} / \mathrm{a}$ & $\mathrm{n} / \mathrm{a}$ & $20 \mathrm{RPM}$ \\
Deposition rate & $1.4 \AA / \mathrm{s}$ & $1.2 \AA / \mathrm{s}$ & $2.6 \AA / \mathrm{s}$ \\
Substrate temperature & $\mathrm{n} / \mathrm{a}$ & $\mathrm{n} / \mathrm{a}$ & $20{ }^{\circ} \mathrm{C}$ \\
\hline
\end{tabular}

The battery fabrication proceeds with the electrodeposition of $\mathrm{Ni}(\mathrm{OH})_{2}$ on the current collector from a $0.08 \mathrm{M} \mathrm{Ni}\left(\mathrm{NO}_{3}\right)_{2}$ solution for 30 minutes, the potential is $-0.9 \mathrm{~V}$ vs. $\mathrm{Ag} / \mathrm{AgCl}(3 \mathrm{M} \mathrm{KCl})$. The $\mathrm{pH}$ value of solution is measured to be 5.6 and remains constant over the deposition time. Hence, there is little concern that the $\mathrm{MH}$ electrode, immersed in the nitrate solution, is irreversibly oxidized. After electrodeposition, the electrodes are thoroughly rinsed with DI water.

The gel electrolyte is prepared as described in detail in Ref. [31]. The procedure starts with dissolving $50 \mathrm{mg}$ of MBA in $10.6 \mathrm{ml}$ acrylic acid, followed 
by drop-wise pouring of $50 \mathrm{ml}$ of $8 \mathrm{M} \mathrm{KOH}$ while the solution is continuously stirred. Acrylic acid is completely neutralized by the $\mathrm{KOH}$ and forms acrylate ions as monomers for the polymerization. The aforementioned solution is highly alkaline with a hydroxide concentration of about $4 \mathrm{M}$. Then, $4 \mu \mathrm{l}$ of a 4 wt. $\% \mathrm{~K}_{2} \mathrm{~S}_{2} \mathrm{O}_{8}$ solution is added as initiator. Having stirred the solution for about $1 \mathrm{~min}, 1 \mu \mathrm{l}$ of the solution is extracted using a micropipette and poured on the electrodes. After the polymerization of the solution, the gel electrolyte is encapsulated inside of the void volume of a thick PDMS film to prevent humidity loss to the surroundings. PDMS precursor and curing agent are therefore mixed at a weight ratio of 10:1. The mixture is then poured into a petri dish containing the (negative) mold of the void space made by several layers of scotch tape ${ }^{\circledR}$.

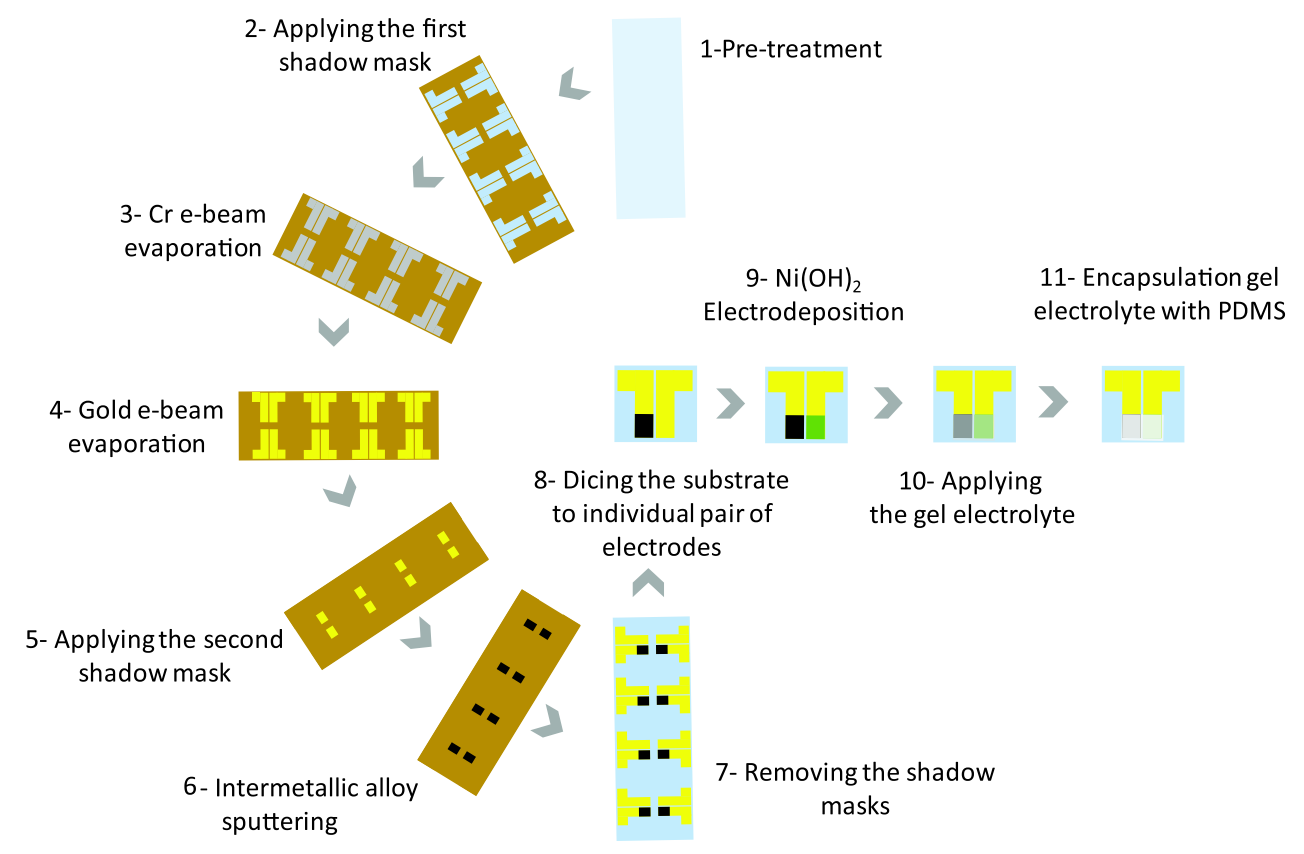

Figure 2: Fabrication process scheme of the Ni-MH microbattery. 


\subsection{Gel electrolyte characteristics}

We compile the EIS data of the gel electrolyte sandwiched between two blocking electrodes in a Nyquist diagram (not shown). The diagram reveals a tail-like segment of a semicircle which is typical for blocking electrodes and reported for other $\mathrm{KOH}-$ based gel electrolytes as well, cf. Ref. [32]. The resistance of the gel electrolyte $R_{G}$ is obtained at the intersection of the high-frequency spectrum with the real axis and found to be $0.22 \Omega \pm 0.004$ $\Omega$. The gel electrolyte resistance is converted to a specific ionic conductivity according to $\sigma=R_{G} l / A$, where $A$ is the electrode area and $l$ is the electrode distance. We arrive in $\sigma=0.22 \mathrm{~S} \mathrm{~cm}^{-1} \pm 0.004 \mathrm{~S} \mathrm{~cm}^{-1}$ which is in good agreement with the value reported in Ref. [31] for a similar polymer gel electrolyte.

An important question comes up when a gel electrolyte is used. How is the influence on the performance of an electrochemical system compared to a liquid electrolyte? In order to make useful comparisons, conductivity and hydroxide activity of the liquid $\mathrm{KOH}$ solution should be equal to those of the gel electrolyte. However, this task cannot be realized. On the one hand, common models to infer activity coefficients are not applicable for ions in a gel matrix. On the other hand, settling with the concentration instead of the activity is not a possibility either. In fact, a $4 \mathrm{M} \mathrm{KOH}$ solution has a two times higher ionic conductivity compared to a $4 \mathrm{M} \mathrm{KOH}$ gel electrolyte polymerized from acrylic acid [31]. In this work, we choose an aqueous 1M $\mathrm{KOH}$ electrolyte for the comparison with the gel. The conductivity of the aqueous $1 \mathrm{M} \mathrm{KOH}$ electrolyte is almost identical to that of the $4 \mathrm{M} \mathrm{KOH}$ gel electrolyte [31]. 
Figure 3 shows the $\mathrm{CVs}$ of the Pt electrode in aqueous 1M KOH (solid line) and in the gel electrolyte (dashed line). The inspection of the liquid electrolyte $\mathrm{CV}$ reveals that it can be divided into roughly four regions distinguished by different electrochemical mechanisms; here, we follow the interpretation of Jerkiewicz [27].

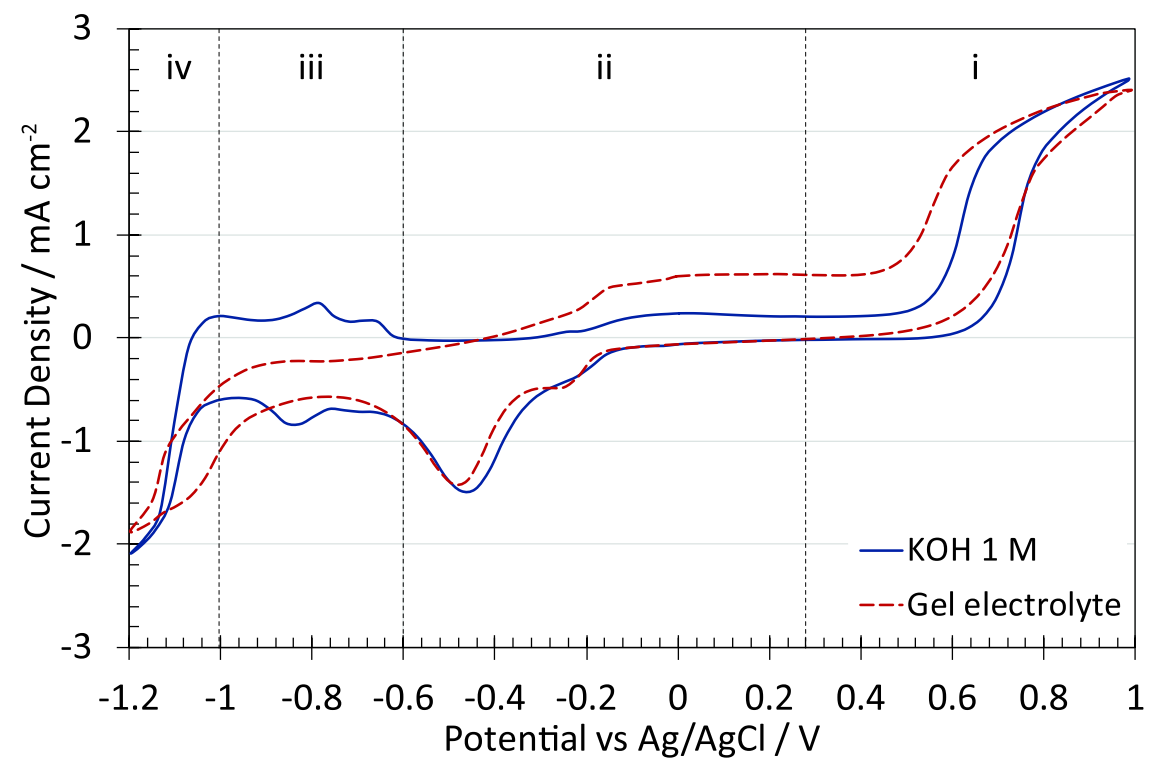

Figure 3: Cyclic voltammogram of a Pt electrode in an aqueous $1 \mathrm{M} \mathrm{KOH}$ and in a gel electrolyte (dashed line) at $\mathrm{T}=298 \mathrm{~K}$ and a scan rate of $\nu=10 \mathrm{mV} \mathrm{s}^{-1}$. The gel electrolyte suppresses the underpotential deposition of the hydrogen.

The first region (labelled $i$ ) contains the oxygen evolution reaction (OER)

$$
2 \mathrm{H}_{2} \mathrm{O}+\mathrm{O}_{2}+4 e^{-} \leftrightarrow 4 \mathrm{OH}^{-} \quad \mathrm{E}^{0}=0.194 \mathrm{~V} \text { vs. } \mathrm{Ag} / \mathrm{AgCl}(3 \mathrm{M} \mathrm{KCl})
$$

Inspection of the CV reveals significant differences between the respective 
peak position and the standard reduction potential. This could be an indication that the reaction occurs with an alternative two-electron pathway, where the hydroxide is first oxidized to peroxide ions at a standard potential of $\mathrm{E}^{0}$ $=0.59 \mathrm{~V}$ vs. $\mathrm{Ag} / \mathrm{AgCl}(3 \mathrm{M} \mathrm{KCl})$, before oxygen is formed in another step [33]. Region " $i i "$ roughly covers the potential range of $-0.6 \mathrm{~V}$ to $0.2 \mathrm{~V}$ and comprises the $\mathrm{PtO}$ formation in anodic direction and the respective reduction during the reverse scan. Part " $i i i$ " of the voltammogram contains two redox peaks at potentials of around $-0.9 \mathrm{~V}$ and $-0.6 \mathrm{~V}$. These peaks are related to the underpotential hydrogen adsorption/desorption which only takes place on the surface of a Pt-group metal. The hydrogen $\mathrm{H}_{U P D}$ generated in the underpotential region has different characteristics compared to that from the neighboring hydrogen evolution reaction (HER) [27]. The last region iv features a cathodic tail-like shape due to the HER where water is reduced according to

$$
2 \mathrm{H}_{2} \mathrm{O}+2 e^{-} \leftrightarrow 2 \mathrm{OH}^{-}+\mathrm{H}_{2} \quad \mathrm{E}^{0}=-1.036 \mathrm{~V} \text { vs. } \mathrm{Ag} / \mathrm{AgCl}(3 \mathrm{M} \mathrm{KCl})
$$

The $\mathrm{CV}$ of the $\mathrm{Pt}$ electrode in the gel electrolyte is performed under similar conditions as in the liquid gel. A comparison between the two CVs reveals several similarities but also differences. In terms of similarities, both voltammograms feature an almost equal reduction peak for the $\mathrm{PtO}$ conversion. Additionally, the HER and the OER can be clearly detected in either case. However, inspection of region of $i$ clarifies that the OER in the gel electrolyte occurs at lower oxidation potentials and the area of the tail is also larger. Likewise, the HER (region $i v$ ) occurs at lower reduction potentials. 
This behavior should be related to the considerably higher concentration of hydroxide in the gel electrolyte compared to the aqueous electrolyte. Both OER and HER are harmful for a battery application since they consume the water in the gel which lowers its conductivity. Furthermore, the generated $\mathrm{H}_{2}$ and $\mathrm{O}_{2}$ are encapsulated as gas bubbles that either cover the electrode surface or lower the gel conductivity. Since these side reactions are inevitable, it is expected that the internal resistance of the microbattery increases over the life time. We further investigate this issue in the context of the EIS measurements as discussed below. There is another significant difference in the CVs since we do not observe the peaks for the underpotential deposition of $\mathrm{H}_{U P D}$ in the electrolyte. The generation of $\mathrm{H}_{U P D}$ not only depends on the hydrophilic-hydrophobic properties of the Pt-electrolyte interface but is also governed by the thermodynamics of the hydrogen chemisorption onto the metal surface [27]. Therefore, we assume that the polymerization additives prevent the generation of $\mathrm{H}_{U P D}$ due to possible changes in the surface properties and/or the free Gibbs energy of $\mathrm{H}_{U P D}$ formation. To summarize, the electrochemical performance of the gel electrolyte shows some moderate variations compared to the aqueous $1 \mathrm{M} \mathrm{KOH}$ solution even though the conductivities are practically the same. The variations are probably related to the difference in $\mathrm{KOH}$ concentration and the additives that are required for the gel polymerization.

\subsection{Electrochemical characterization of the electrodes}

Figure 4a shows the $\mathrm{CV}$ of the $\mathrm{Ni}(\mathrm{OH})_{2}$ thin-film electrode immersed in an aqueous $1 \mathrm{M} \mathrm{KOH}$ solution. The cathodic peak can be clearly identified while the anodic peak is partially covered by a tail which is present at potentials 

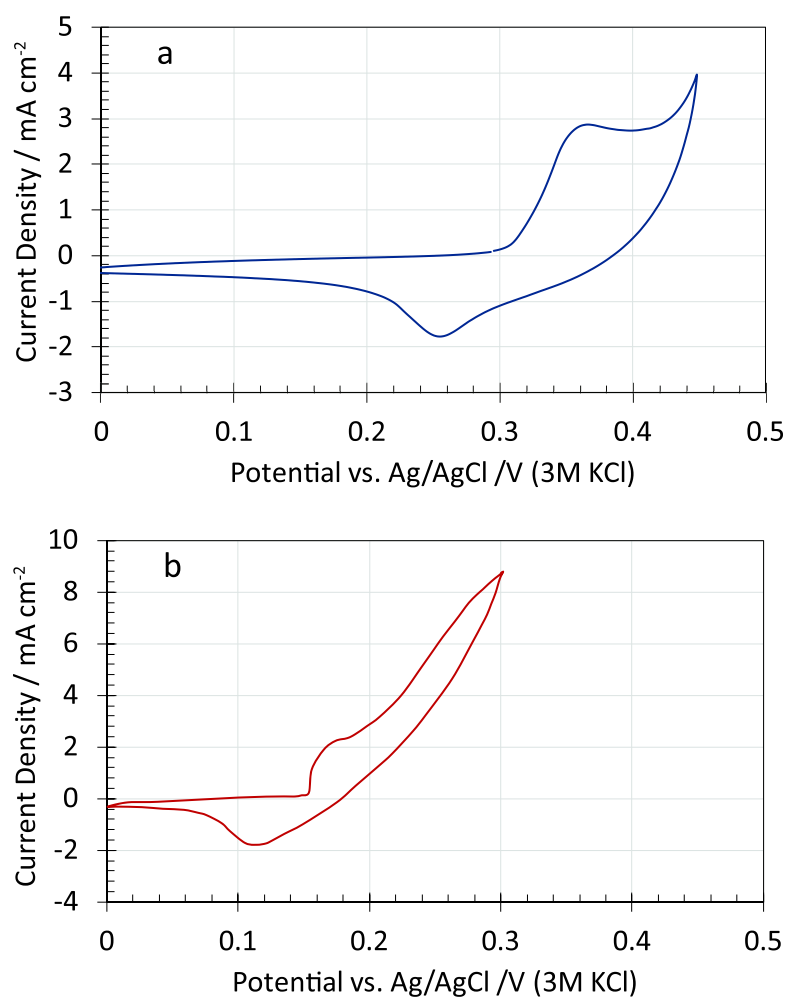

Figure 4: Cyclic voltammograms of the $\mathrm{Ni}(\mathrm{OH})_{2}$ thin-film electrode in a) aqueous $1 \mathrm{M}$ $\mathrm{KOH}$ and $\mathrm{b}$ ) the gel electrolyte at $\mathrm{T}=298 \mathrm{~K}$ and a scan rate of $\nu=10 \mathrm{mV} \mathrm{s}^{-1}$. The gel promotes the oxygen evolution reaction.

around $0.4 \mathrm{~V}$. Comparison with the standard reduction potential shows that the anodic tail can be assigned to the OER, cf. reaction (1). The CV is in a good agreement with those in our previous work where we investigated micro-patterned $\mathrm{Ni}(\mathrm{OH})_{2}$ film electrodes [34]. The cathodic and anodic peak potentials are $\mathrm{E}_{c}=0.37 \mathrm{~V}$ and $\mathrm{E}_{a}=0.26 \mathrm{~V}$, respectively. Hence, the formal reduction potential is $\mathrm{E}_{1 / 2}=0.315 \mathrm{~V}$ confirming that the observed reaction 
corresponds to

$\mathrm{NiOOH}+\mathrm{H}_{2} \mathrm{O}+e^{-} \rightleftharpoons \mathrm{Ni}(\mathrm{OH})_{2}+\mathrm{OH}^{-} \quad \mathrm{E}^{0}=0.30 \mathrm{~V}$ vs. $\mathrm{Ag} / \mathrm{AgCl}(3 \mathrm{M} \mathrm{KCl})$

Figure $4 \mathrm{~b}$ shows the $\mathrm{CV}$ of the $\mathrm{Ni}(\mathrm{OH})_{2}$ thin-film electrode immersed in the gel electrolyte. A cathodic peak can be clearly identified at a potential of $\mathrm{E}_{c}=0.11 \mathrm{~V}$. The corresponding anodic peak at $\mathrm{E}_{a}=0.18 \mathrm{~V}$ has an arc-like shape due to the overlap with the peak of the OER. Generally, we observe that all redox reactions are shifted to lower potentials. This shift is very pronounced for the OER and since we observe much higher current densities compared to the liquid electrolyte. The promotion of the OER can be easily explained by inspection of reaction (1), where a higher hydroxide concentration, as this is the case in the gel, advances the reaction in the oxidation direction. Hence, we perform the $\mathrm{CV}$ in the gel with a narrower potential window to prevent excessive oxygen generation which would deteriorate the gel electrolyte. Regarding the peak potentials of the $\mathrm{Ni}(\mathrm{OH})_{2}$ conversion, we can also argue that the shift to lower values is related to the gel's higher hydroxide concentration. In fact, the reaction quotient of reaction (3) decreases with the hydroxide concentation which, according to the Nernst equation, lowers the formal reduction potential

The CV of the $\mathrm{MH}$ thin-film electrode immersed in an aqueous $1 \mathrm{M} \mathrm{KOH}$ solution is given in Fig. 5a. We identify an anodic peak at a potential of $\mathrm{E}_{a}$ $=-0.81 \mathrm{~V}$. The corresponding cathodic peak, located around $\mathrm{E}_{c} \approx-1 \mathrm{~V}$, is more or less covered by a very pronounced tail present at lower potentials. The peak positions clarify that the redox peaks are related to the reduction 

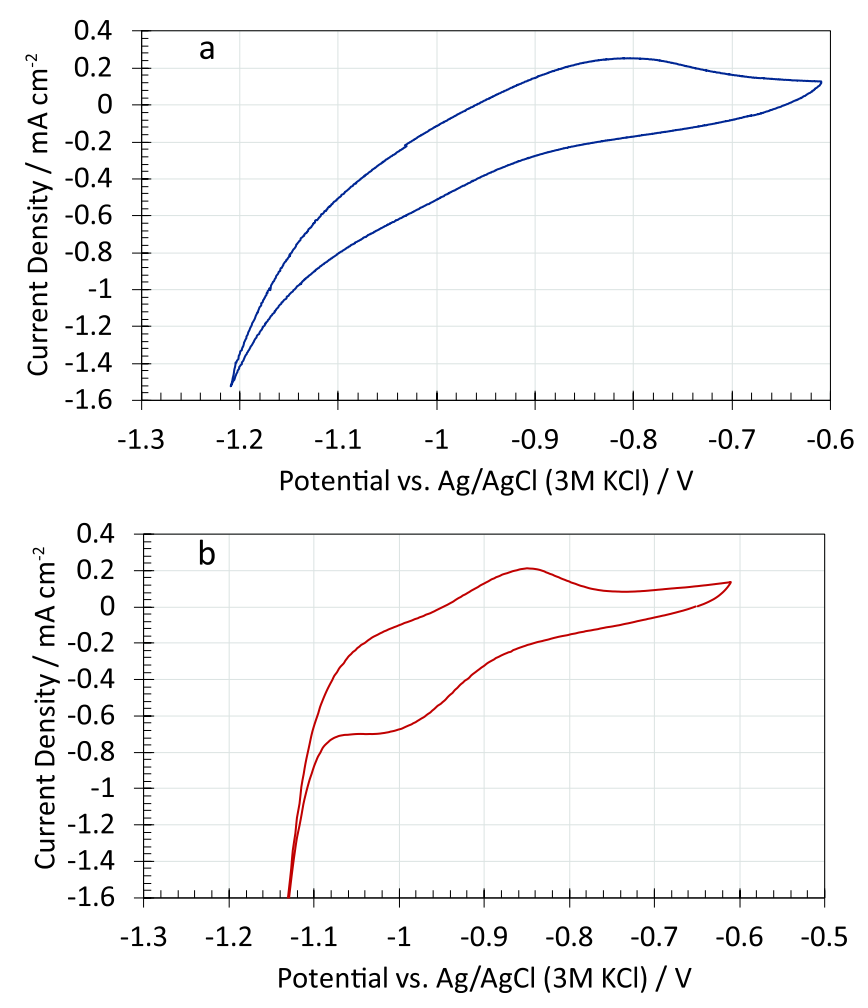

Figure 5: Cyclic voltammogram of the metal hydride thin-film electrode in a) $1 \mathrm{M} \mathrm{KOH}$ and b) in the gel electrolyte at $\mathrm{T}=298 \mathrm{~K}$ and a scan rate of $\nu=10 \mathrm{mV} \mathrm{s}^{-1}$. The gel diminishes the hydrogen evolution reaction.

of water at the electrode surface according to

$\mathrm{M}+\mathrm{H}_{2} \mathrm{O}+e^{-} \rightleftharpoons \mathrm{MH}_{\text {ads }}+\mathrm{OH}^{-} \quad \mathrm{E}^{0}=-1.10 \mathrm{~V}$ vs. $\mathrm{Ag} / \mathrm{AgCl}(3 \mathrm{M} \mathrm{KCl})$

The tail in the CV is induced by the HER according to reaction (2). Additionally, the adsorbed hydrogen at the surface of MH electrode may be consumed via the Heyrovsky reaction in alkaline media

$$
\mathrm{MH}_{\text {ads }}+\mathrm{H}_{2} \mathrm{O}+e^{-} \rightleftharpoons \mathrm{M}+\mathrm{H}_{2}+\mathrm{OH}^{-},
$$


which prevents its absorption in the lattice.

The CV of the MH thin-film electrode in the alkaline gel electrolyte is given in Fig. 5b. We observe a more pronounced anodic peak that is shifted to a somewhat more negative potential of $\mathrm{E}_{a}=-0.84 \mathrm{~V}$. Interestingly, the cathodic peak, located around $\mathrm{E}_{a} \approx-1$, is also more pronounced and now can be clearly distinguished form the HER. Additionally, we notice that the HER tail has a considerably smaller area compared to the $\mathrm{CV}$ in the liquid electrolyte. The differences between $\mathrm{CV}$ in gel and liquid electrolyte should also be related to the higher hydroxide concentration in the gel electrolyte which shifts the equilibrium of reactions (2) and (4) towards the oxidation side (lower potentials). The voltammogram $5 \mathrm{~b}$ also shows the inhibition of the HER and a more pronounced peak related to the electroreduction of water. This could be related to the gel additives as well as to possible different reaction mechanisms in gel and liquid electrolyte. Nevertheless, the suppression of the HER is a welcome outcome for a microbattery application since it mitigates desiccation of the electrolyte as well as gas formation. Still, at potentials lower than around $-1.1 \mathrm{~V}$, there is a significant cathodic current due to the HER. This indicates that care should be taken when the battery is discharged to avoid operation at potentials where the HER occurs.

\subsection{Galvanostatic charge-discharge of the microbattery}

In this section, we provide insights into the charge-discharge characteristics and the cyclability of the microbattery. The (discharge) performance of a $\mathrm{Ni}-\mathrm{MH}$ battery relies on the conversion of nickel oxyhydroxide $\mathrm{NiOOH}$ to nickel hydroxide $\mathrm{Ni}(\mathrm{OH})_{2}$ and the electrolytic dehydrogenation of the $\mathrm{MH}$ 
film. The overall reaction is given by the combination of reactions (3) and (4) according to

$$
\mathrm{MH}+\mathrm{NiOOH} \rightleftharpoons \mathrm{M}+\mathrm{Ni}(\mathrm{OH})_{2} \quad E_{\mathrm{Cell}}^{0}=1.40 \mathrm{~V} .
$$

The fact that either electrode reaction involves hydroxide makes a separator obsolete and also allows for a coplanar battery design. The chargedischarge properties are tested at a current density of $1 \mathrm{~mA} \mathrm{~cm}^{-2}$. Generally, Ni-MH batteries need multiple charge-discharge cycles to produce a more or less constant capacity due to an initial pulverization of the $\mathrm{MH}$ electrode $[35,36]$. Hence, we perform a conditioning step consisting of 3 charge-discharge cycles before performing the actual measurements. Preliminary charge-discharge tests also show that overcharging deteriorates the gel electrolyte due to conditions (overpotentials) that trigger OER and HER. These side reaction do not only lower the battery efficiency but also consume water inside of the gel electrolyte lowering its conductivity. Additionally, we observe that after (continuous) overcharging the $\mathrm{Ni}(\mathrm{OH})_{2}$ thin-film starts to shrink and peels of the current collector. In order to minimize cell degeneration, it is necessary to suppress the side reactions by defining an appropriate potential window for the charge and discharge cycles. The Ni electrode is more prone to overcharging and therefore it is designed with a higher capacity than the $\mathrm{MH}$ electrode in order to inhibit the OER. We estimate that 30 min of $\mathrm{Ni}(\mathrm{OH})_{2}$ electrodeposition creates an electrode with a roughly ten times higher theoretical coulombic capacity than the $\mathrm{MH}$ film which keeps the state of charge (SOC) of the Ni electrode always low. After a certain charge duration, we also find that bubbles are formed on $\mathrm{MH}$ electrode when the cell potential is higher than $1.4 \mathrm{~V}$. The gas formation is related to the 
HER and, in conjunction with the varying electrode potential of a MH electrode with the degree of hydrogenation (cf. e.g. [30]), implies that the $\mathrm{MH}$ electrode is more or less fully charged. Hence, we choose the cut-off potential for the charging to be $1.4 \mathrm{~V}$. Regarding discharge, we set the cut-off potential to be $0.85 \mathrm{~V}$.

Figure 6 shows the first 10 cycles of a series of 100 charge-discharge cycles. Since the microbattery capacity is limited by the MH electrode, the results are reported and scaled with its footprint area. As can be seen in Fig. 6, the

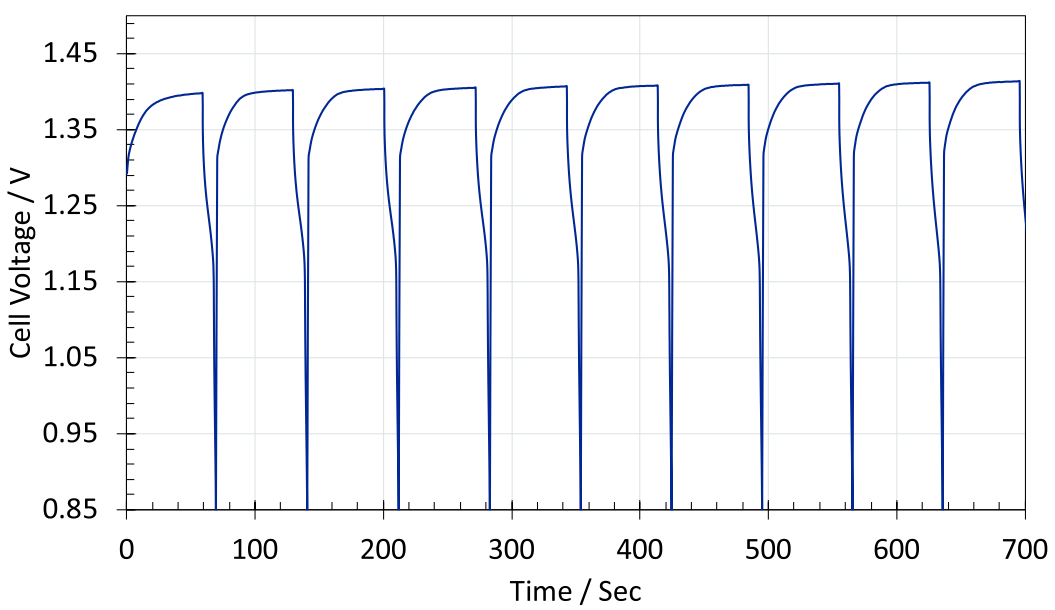

Figure 6: Charge and discharge behavior of the Ni-MH microbattery with a (dis)charge current density of $1 \mathrm{~mA} \mathrm{~cm}^{-2}$. Displayed are the first 10 cycles of a series of 100 .

cell potential gradually increases during the charge process until a plateau is reached. This behavior should be related to the different SOC of the electrodes. The MH electrode is quickly more or less fully charged with a SOC of around 1. Then, the hydrogen that is generated due to reaction (4) cannot be absorbed anymore but forms gas bubbles according to the Tafel and/or the Heyrovsky reaction. Thus, the overpotential at the MH electrode 
does hardly change. At the same time, the Ni electrode maintains a low SOC which results in a more or less constant overpotential too. After charging, the cell potential is measured at no current condition and the OCV is found to be $1.38 \mathrm{~V}$ which is close to the standard cell potential, cf. reaction (6).

The capacity of the microbattery is calculated by integrating the current density over the discharge time divided by the $\mathrm{MH}$ electrode thickness. We compute a discharge capacity of $2.8 \mu \mathrm{Ah} \mathrm{cm}^{-2} \mu \mathrm{m}^{-1}$ at a current density of 1 $\mathrm{mA} \mathrm{cm}{ }^{-2}$. This capacity is significantly lower than the theoretical coulombic capacity of the $\mathrm{MH}$ film which can be explained with different mechanisms. First and foremost, when we consider the gravimetric current density, the battery is discharged at a very high rate. It is known that the capacity of MH electrodes significantly decreases with increasing current density [37]. We estimate the mass-specific current density to be $1200 \mathrm{~mA} \mathrm{~g}^{-1}$ based on a film density of $8.34 \mathrm{~g} \mathrm{~cm}^{-3}$, cf. Ref. [30]. Additionally, the coplanar design generally results in a lower capacity compared to a corresponding sandwichlike design due to the higher internal resistance [38].

The coulombic efficiency - the ratio of extracted to added charge in a chargedischarge cycle - is found to be only $25 \%$. This relatively low coulombic efficiency is also related to the high gravimetric current density which increases the cell irreversibilities including the charge transfer resistances $[39,40]$. The operation of conventional Ni-MH batteries at current densities around 1200 $\mathrm{mA} \mathrm{g}^{-1}$ already lowers the efficiency to around $60 \%$ [40]. Conventional electrodes are generally made from particulate intermetallic alloys that are addionally microencapsulated by blending with another metal, such as copper, in order to lower the charge transfer resistance. Without microencapsulation, 
like in our case of a sputtered intermetallic alloy film, the efficiency can drop down to $10 \%$ even at moderate current densities [39].

Additionally to the high gravimetric current density, a considerable fraction of the current is consumed by the side reactions. During charging of the microbattery, the cell potential reaches a plateau at around 1.40 volts; a condition where also the HER considerably takes place. We perform additional galvanostatic charge-discharge measurements at the same current density but with a narrower potential window between $0.85 \mathrm{~V}$ to $1.35 \mathrm{~V}$ to diminish excessive side reactions (results not shown). In this case, we determine the coulombic efficiency to be $60.5 \%$. However, this improvement in efficiency comes at the cost of a $35 \%$ drop in capacity. Another more practical improvement in terms coulombic efficiency is feasible by increasing the $\mathrm{MH}$ electrode thickness in order to lower the gravimetric current density.

We also observe that the microbattery is discharged under open circuit conditions. The rate of self-discharge varies with each battery that we manufacture and characterize. This phenomenon is related to a leakage current that in microbatteries can mainly be attributed to a variety of fabrication defects $[22,41,42]$. The electrodes may not be exactly fabricated on the predefined area which is especially critical for our coplanar design where the electrode gap is much less than a millimeter. These fabrication inaccuracies result in locations with a diminished or even short-circuited resistance path which facilitates the self-discharge of the cell. This unwanted behaviour can be addressed by using a separator or a larger spacing between the coplanar electrodes. However, this comes at the cost of an increased internal resistance 
of the cell and the related loss in efficiency.

With respect to cycle life, it is observed that the capacity is lowered by around $40 \%$ after 100 cycles. We mainly attribute this capacity loss to the degradation of the gel electrolyte. Further insights into the degradation are given impedance spectroscopy section.

To summarize the outcome of the charge-discharge investigations: The microbattery features an energy density of $3.34 \mu \mathrm{Wh} \mathrm{cm}{ }^{-2} \mu \mathrm{m}^{-1}$ for a (nominal) power density of $1200 \mu \mathrm{W} \mathrm{cm}-2 \mu \mathrm{m}^{-1}$. This perfomance is sufficient for various remote sensing systems as discussed in Section 1 and is comparable with the data that is typically reported for zinc-nickel microbatteries $[43,44,18,15]$. We also determine a capacity of $2.78 \mu \mathrm{Ah} \mathrm{cm}^{-2} \mu \mathrm{m}^{-1}$ which is not sufficient to compete with (novel) lithium-ion based microbatteries. For example, the printed $\mathrm{LiFePO}_{4}$ film electrodes reported in Ref.[13] provides a four times higher capacity. The 3D lithium-ion microbattery reported in Ref. [14] has a capacity of around $70 \mu \mathrm{Ah} \mathrm{cm}^{-2} \mu \mathrm{m}^{-1}$. Nevertheless, lithium-ion based microbatteries require a more complex cell fabrication and encapsulation which can make the integration into a microsystems more challenging. In contrast, our Ni-MH microbattery has a rather simple design and can be manufactured with relatively straightforward means which makes it attractive for applications with ultra-low power demands.

The polarization of the microbattery is investigated with discharge measurements at different current densities. Here, the microbattery is initially charged at a current density of $1 \mathrm{~mA} \mathrm{~cm}{ }^{-2}$ until the cell potential reaches 


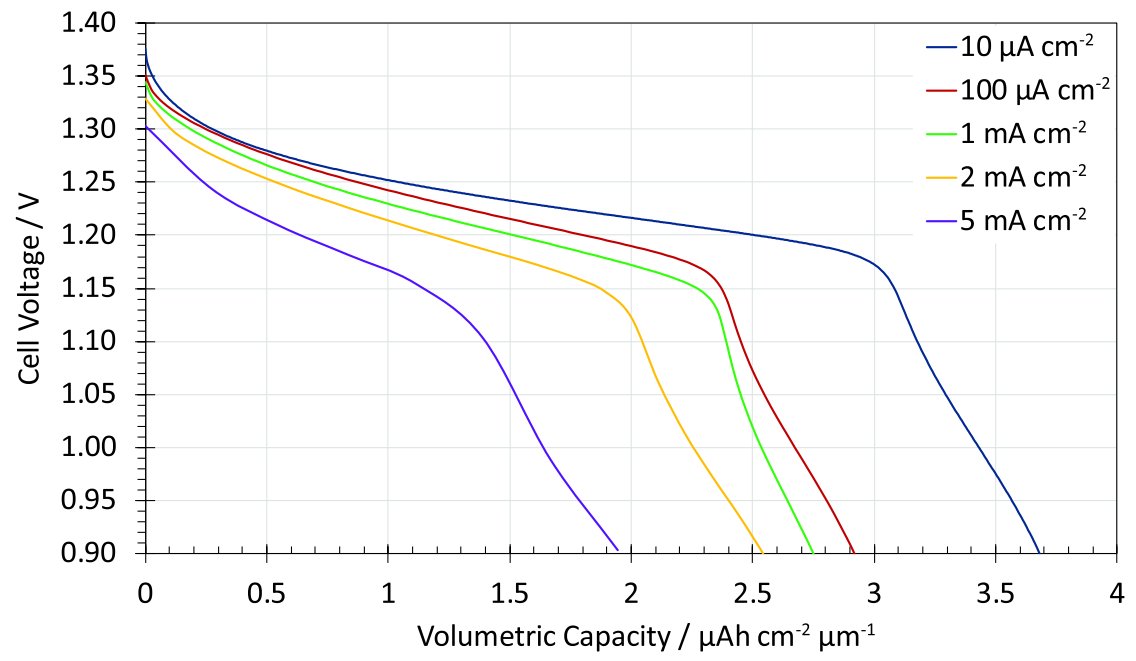

Figure 7: Discharge profile of the Ni-MH microbattery at different current densities ranging from $10 \mu \mathrm{A} \mathrm{cm}^{-2}$ to $5 \mathrm{~mA} \mathrm{~cm}{ }^{-2}$. The volumetric capacity decreases with increasing discharge current density.

$1.4 \mathrm{~V}$. After the stabilization of the OCV (potential variation $<0.1 \mathrm{mV} / \mathrm{s}$ ), the microbattery is discharged with a constant current density until a potential of $0.9 \mathrm{~V}$ is reached. The results are given in form of capacity curves in Fig. 7. Independent of the discharge current density, we observe that all different curves have a similar shape. Initially, the cell potential drops slowly over the capacity which is directly proportional to the discharge time. After a certain discharge time, the potential drop considerably increases due to higher mass transfer resistances that build up when the hydrogen content of the intermetallic is almost spent. As expected, the overall (maximum) capacity decreases with increasing discharge rate. For the lowest and highest current density, we observe a capacity of around 3.7 and $2 \mu \mathrm{Ah} \mathrm{cm}^{-1} \mu \mathrm{m}^{-1}$, respectively. In other words, for a current density increase by 500 times, we 
observe a capacity loss of $45 \%$.

In contrast, we still observe a reasonably good discharge rating capability of our microbattery which is related to the high surface area-to-volume ratio of around $10^{4} \mathrm{~cm}^{-1}$ of the $\mathrm{MH}$ thin-film. In $\mathrm{MH}$ electrodes, there are two (limiting) mass transfer resistances during discharge: The diffusion of the absorbed hydrogen molecules through the electrode i) bulk and the ii) interface. A higher discharge rate increases hydrogen (charge) transfer resistance. Likewise, the bulk diffusion towards the surface triggers a potential drop due to mass transfer polarization $[45,46]$. Both effects cause the drop in capacity. However, in our case of a film with a very high surface-to-area ratio, most of the hydrogen is located in the vicinity of the interface which reduces the resistance related to bulk diffusion. As a result, the discharge rating capability is improved at the expense of a lower capacity.

\subsection{Electrochemical impedance spectroscopy}

We perform EIS measurements after 3, 50 and 100 charge-discharge cycles at OCV. The respective results are given in Fig. 8 in form of a Nyquist plot. Comparison of the different spectra reveals that they share a similar trend. Generally, the spectra consists of segments of two overlapping semicircles. The first semicircle is observed at relatively high frequencies and is usually associated with the contact between active materials and current collector, and surface properties of the (hydride layer) electrodes. At low frequency range, a segment of another semicircle appears which can be attributed to the electrochemical reactions at the electrodes [47]. Figure 8 clearly reveals that the microbattery impedance gradually increases with increasing number of charge-discharge cycles. This effect is associated with electrode and hy- 
drogel degradation which can be quantitatively investigated by a regression of the spectra to an equivalent electrical circuit (EEC). We propose an EEC consisting of three linear and three nonlinear elements given as an insert in Fig. 8. The proposed EES is inspired by the circuit introduced by Slepsky et al. for a (macroscopic) Ni-MH battery [47]. However, we are not able to fit our spectra to their EEC with the required quality. Hence, we use the same description for the Ni electrode but modify the description of the $\mathrm{MH}$ electrode. Our proposed EEC consists of a resistor $R_{\text {ohm }}$ in series with the parallel combination of a constant phase element $C P E$ and another resistor $R_{C T 1}$, in series with a sub-circuit consisting of a parallel arrangement of a capacitor $C$ and a Warburg element $W$ in series with a resistor $R_{C T 2}$.

Here, $R_{\text {ohm }}$ represents the ohmic resistances in the microbattery. That is, the resistance of gel electrolyte, contact resistance of current collectors, wires as well as the contact resistances between the electrolyte and electrodes. The parallel combination of $C P E$ and $R_{C T 1}$ describes the Ni electrode while the sub-circuit represents the $\mathrm{MH}$ electrode. Note that the electrodes are convoluted which makes the spectra interpretation difficult.

From the regression results, we can infer that the charge transfer resistances, $R_{C T 1}$ and $R_{C T 2}$ have a significant contribution to the impedance and are, independent of the cycle number, around ten times higher compared to $R_{o h m}$. This might be a result of the high surface-to-volume-ratio of the thinfilm electrodes which promotes oxidation of the interfaces. Evaluation of the degradation process is made by comparison of the regression parameter. For the third cycle, $R_{\text {ohm }}$ is found to be $9.7 \Omega$. It increases to $21.1 \Omega$ and 24.4 $\Omega$ after 50 and 100 cycles, respectively. The 2.5 fold increase of the ohmic 


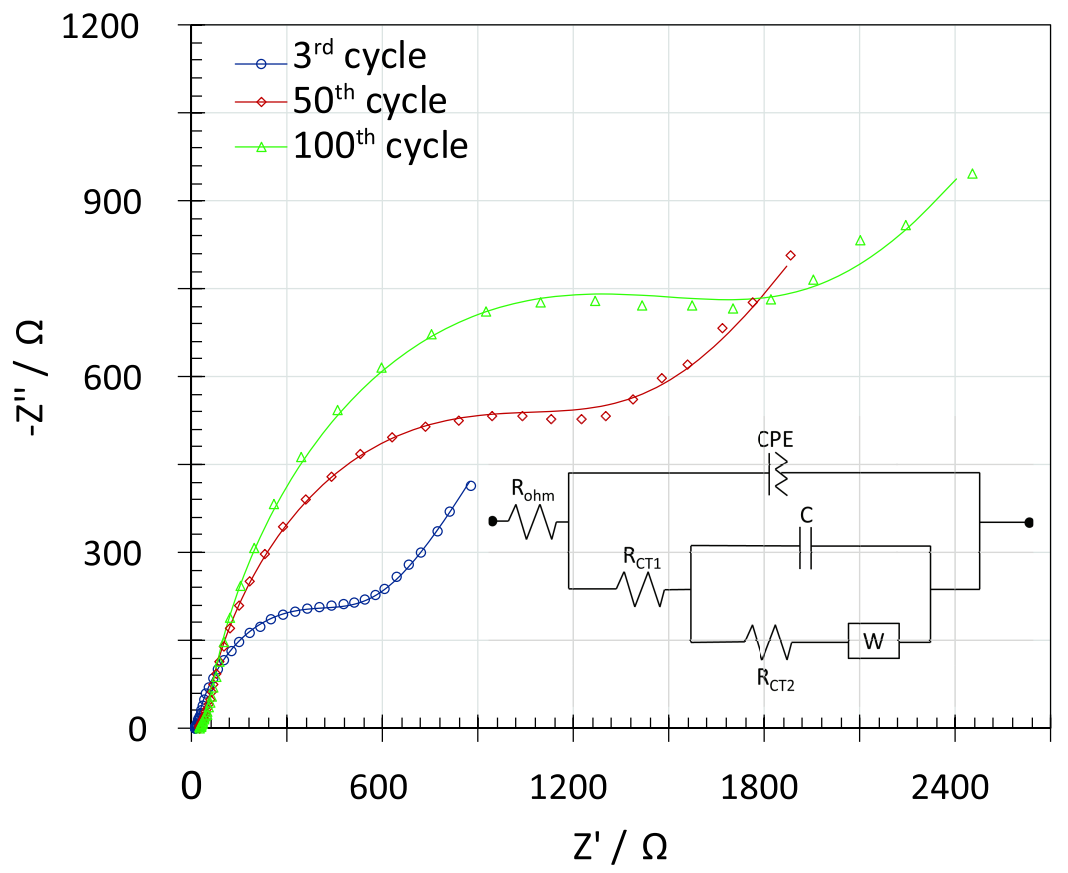

Figure 8: Nyquist diagram of the microbattery for the $3^{r d}, 50^{t h}$ and $100^{t h}$ charge-discharge cycle at frequency range of $100 \mathrm{kHz}$ to $10 \mathrm{mHz}$. Symbols depict experimental data while lines represent the results of the regression to the equivalent electrical circuit. The overall impedance increases with increasing number of charge-discharge cycles.

resitor after 100 cycles should be related to the humidity loss of the gel electrolyte due to the side reactions as they irreversibly consume water molecules and produce gas bubbles; cf. earlier discussion. Regarding the other electrical components, it is observed that their impedances also increase with the cycle number. This behavior could be related to the degradation of the electroactive materials. Further comparison of the results reveals that the relative increase of all element impedances is approximately equal to the relative variation in $R_{\text {ohm }}$. We conclude that a promising path to extend the 
life time of the microbattery is any improvement that enhances the longevity of the gel electrolyte; e.g., the suppression of the unwanted side reactions.

\section{Conclusion}

In this work, we report on the fabrication of a novel coplanar nickelmetal hydride microbattery with a gel electrolyte that is fabricated on a glass substrate. The fabrication process is based on different thin-film deposition processes which are common in the MEMS industry and therefore enable the easy battery integration during manufacturing of the microsystem. The main conclusions of our work are:

1. Comparison of voltammograms of the nickel electrode in liquid and gel electrolyte reveals that the gel promotes the oxygen evolution reaction. This results in the deterioration of the nickel electrode when the microbattery is overcharged. In order to increase the battery life time, a narrow potential range for the charge and discharge protocol and larger nickel electrode capacity is recommended.

2. The Ni-MH microbattery is cycled at a current density of $1 \mathrm{~mA} \mathrm{~cm}^{-2}$ for 100 cycles. The capacity and average cell potential during discharge are found to be $2.78 \mu \mathrm{Ah} \mathrm{cm}^{-2} \mu \mathrm{m}^{-1}$. The microbattery features an energy density of $3.34 \mu \mathrm{Wh} \mathrm{cm}^{-2} \mu \mathrm{m}^{-1}$ for a (nominal) power density of $1200 \mu \mathrm{W} \mathrm{cm} \mathrm{cm}^{-2} \mu \mathrm{m}^{-1}$ which is sufficient for various remote sensing systems.

3. After 100 charge-discharge cycles, the capacity is decreased by $40 \%$. This is mainly due to the increase of the ohmic resistance of the gel electrolyte as well as deterioration of the metal hydride film which 
is confirmed by the results of the Electrochemical Impedance Spectroscopy.

4. The microbattery is discharged at current densities ranging from $10 \mu \mathrm{A}$ $\mathrm{cm}^{-2}$ to $5 \mathrm{~mA} \mathrm{~cm}^{-2}$. The capacity of the microbattery decreases by 45 $\%$ when the current density increases by 500 times. In contrast, we still observe a reasonably good discharge rating capability which is related to the high surface area-to-volume ratio of the metal hydride thin-film.

5. With respect to future work, our results imply that any improvement of the gel improves the life time of the microbattery. Additionally, an increase of the metal hydride electrode thickness should mitigate some of the specific capacity loss that we observe compared to conventional electrodes.

\section{Acknowledgements}

The authors gratefully acknowledge the financial support from the Natural Sciences and Engineering Research Council of Canada (NSERC) and an Ontario Early Researcher Award for D.P.J.B. We also thank NanoFabrication Kingston for support.

\section{References}

[1] J. H. Pikul, J. Liu, P. V. Braun, W. P. King, Integration of high capacity materials into interdigitated mesostructured electrodes for high energy and high power density primary microbatteries, Journal of Power Sources 315 (2016) 308-315. 
[2] A. T. Kutbee, R. R. Bahabry, K. O. Alamoudi, M. T. Ghoneim, M. D. Cordero, A. S. Almuslem, A. Gumus, E. M. Diallo, J. M. Nassar, A. M. Hussain, et al., Flexible and biocompatible high-performance solid-state micro-battery for implantable orthodontic system, npj Flexible Electronics 1 (1) (2017) 7.

[3] J. Oudenhoven, R. Vullers, R. Schaijk, A review of the present situation and future developments of micro-batteries for wireless autonomous sensor systems, International Journal of Energy Research 36 (12) (2012) 1139-1150.

[4] B. L. Ellis, P. Knauth, T. Djenizian, Three-dimensional self-supported metal oxides for advanced energy storage, Advanced Materials 26 (21) (2014) 3368-3397.

[5] P. H. Humble, J. N. Harb, R. LaFollette, Microscopic nickel-zinc batteries for use in autonomous microsystems, Journal of the Electrochemical Society 148 (12) (2001) A1357-A1361.

[6] R. Puers, P. Wouters, Adaptable interface circuits for flexible monitoring of temperature and movement, Analog Integrated Circuits and Signal Processing 14 (3) (1997) 193-206.

[7] A. P. Chandrakasan, N. Verma, D. C. Daly, Ultralow-power electronics for biomedical applications, Annual Review of Biomedical Engineering 10.

[8] H. Okada, T. Itoh, T. Masuda, Development of custom CMOS LSI for 
ultra-low power wireless sensor node in health monitoring systems, in: Sensors, 2011 IEEE, 2011, pp. 1197-1200.

[9] H. Okada, H. Nogami, T. Kobayashi, T. Masuda, T. Itoh, Development of ultra low power wireless sensor node with piezoelectric accelerometer for health monitoring, in: 2013 Transducers Eurosensors XXVII: The 17th International Conference on Solid-State Sensors, Actuators and Microsystems (TRANSDUCERS EUROSENSORS XXVII), 2013, pp. 26-29.

[10] Y. Lee, B. Giridhar, Z. Foo, D. Sylvester, D. B. Blaauw, A sub-nW multi-stage temperature compensated timer for ultra-low-power sensor nodes, IEEE Journal of Solid-State Circuits 48 (10) (2013) 2511-2521.

[11] T. S. Arthur, D. J. Bates, N. Cirigliano, D. C. Johnson, P. Malati, J. M. Mosby, E. Perre, M. T. Rawls, A. L. Prieto, B. Dunn, Three-dimensional electrodes and battery architectures, MRS Bulletin 36 (7) (2011) 523531.

[12] K. Cook-Chennault, N. Thambi, A. Sastry, Powering MEMS portable devices: A review of non-regenerative and regenerative power supply systems with special emphasis on piezoelectric energy harvesting systems, Smart Materials and Structures 17 (4) (2008) 043001.

[13] P.-E. Delannoy, B. Riou, T. Brousse, J. Le Bideau, D. Guyomard, B. Lestriez, Ink-jet printed porous composite $\mathrm{LiFePO}_{4}$ electrode from aqueous suspension for microbatteries, Journal of Power Sources 287 (2015) 261-268. 
[14] G. D. Salian, C. Lebouin, A. Demoulin, M. Lepihin, S. Maria, A. Galeyeva, A. Kurbatov, T. Djenizian, Electrodeposition of polymer electrolyte in nanostructured electrodes for enhanced electrochemical performance of thin-film Li-ion microbatteries, Journal of Power Sources 340 (2017) 242-246.

[15] K. Gerasopoulos, M. McCarthy, E. Royston, J. N. Culver, R. Ghodssi, Nanostructured nickel electrodes using the tobacco mosaic virus for microbattery applications, Journal of Micromechanics and Microengineering 18 (10) (2008) 104003.

[16] N. Vellaluru, Y. B. Gianchandani, T. Li, Facile batch mode process for high capacity rechargeable nickel-zinc microbatteries, in: 2017 19th International Conference on Solid-State Sensors, Actuators and Microsystems (TRANSDUCERS), 2017, pp. 1867-1870.

[17] K. B. Lee, L. Lin, Electrolyte-based on-demand and disposable microbattery, Journal of Microelectromechanical Systems 12 (6) (2003) 840847.

[18] F. Chamran, Y. Yeh, H.-S. Min, B. Dunn, C.-J. Kim, Fabrication of high-aspect-ratio electrode arrays for three-dimensional microbatteries, Journal of Microelectromechanical Systems 16 (4) (2007) 844-852.

[19] A. Armutlulu, Y. Fang, S. Kim, C. Ji, S. B. Allen, M. Allen, A MEMSenabled 3D zinc-air microbattery with improved discharge characteristics based on a multilayer metallic substructure, Journal of Micromechanics and Microengineering 21 (10) (2011) 104011. 
[20] F. Albano, Y. Lin, D. Blaauw, D. Sylvester, K. Wise, A. Sastry, A fully integrated microbattery for an implantable microelectromechanical system, Journal of Power Sources 185 (2) (2008) 1524-1532.

[21] C. C. Ho, K. Murata, D. A. Steingart, J. W. Evans, P. K. Wright, A super ink jet printed zinc-silver 3D microbattery, Journal of Micromechanics and Microengineering 19 (9) (2009) 094013.

[22] C. C. Ho, J. W. Evans, P. K. Wright, Direct write dispenser printing of a zinc microbattery with an ionic liquid gel electrolyte, Journal of Micromechanics and Microengineering 20 (10) (2010) 104009.

[23] J.-S. Do, S.-H. Yu, S.-F. Cheng, Thick-film nickel-metal-hydride battery based on porous ceramic substrates, Journal of Power Sources 117 (1-2) (2003) 203-211.

[24] J.-S. Do, S.-H. Yu, S.-F. Cheng, Preparation and characterization of thick-film Ni/MH battery, Biosensors and Bioelectronics 20 (1) (2004) $61-67$.

[25] X.-P. Gao, H.-X. Yang, Multi-electron reaction materials for high energy density batteries, Energy \& Environmental Science 3 (2) (2010) 174-189.

[26] J. Liu, M. Chen, L. Zhang, J. Jiang, J. Yan, Y. Huang, J. Lin, H. J. Fan, Z. X. Shen, A flexible alkaline rechargeable Ni/Fe battery based on graphene foam/carbon nanotubes hybrid film, Nano Letters 14 (12) (2014) 7180-7187.

[27] G. Jerkiewicz, Electrochemical hydrogen adsorption and absorption. 
part 1: Under-potential deposition of hydrogen, Electrocatalysis 1 (4) (2010) 179-199.

[28] S. Szilasi, L. Juhasz, Selective etching of PDMS: Etching as a negative tone resist, Applied Surface Science 447 (2018) 697-703.

[29] S. Szilasi, C. Cserháti, Selective etching of PDMS: Etching technique for application as a positive tone resist, Applied Surface Science 457 (2018) 662-669.

[30] A. Khazaeli, H. Falahati, D. P. Barz, Electrochemical investigation and modelling of $\mathrm{LaNi}_{4.77} \mathrm{Al}_{0.23}$ thin-films sputtered on glass wafers, Journal of Alloys and Compounds 772 (2019) 199 - 208.

[31] X. Zhu, H. Yang, Y. Cao, X. Ai, Preparation and electrochemical characterization of the alkaline polymer gel electrolyte polymerized from acrylic acid and KOH solution, Electrochimica Acta 49 (16) (2004) 25332539 .

[32] L. Fan, J. Chen, G. Qin, L. Wang, X. Hu, Z. Shen, Preparation of PVA-KOH-Halloysite nanotube alkaline solid polymer electrolyte and its application in Ni-MH battery, International Journal of Electrochemical Science 12 (2017) 5142-5156.

[33] X. Ge, A. Sumboja, D. Wuu, T. An, B. Li, F. T. Goh, T. A. Hor, Y. Zong, Z. Liu, Oxygen reduction in alkaline media: from mechanisms to recent advances of catalysts, ACS Catalysis 5 (8) (2015) 4643-4667.

[34] H. Falahati, E. Kim, D. P. Barz, Fabrication and characterization of 
thin film nickel hydroxide electrodes for micropower applications, ACS Applied Materials \& Interfaces 7 (23) (2015) 12797-12808.

[35] J. Liu, Y. Yang, Y. Li, P. Yu, Y. He, H. Shao, Comparative study of $\mathrm{LaNi}_{4.7} \mathrm{M}_{0.3}(\mathrm{M}=\mathrm{Ni}, \mathrm{Co}, \mathrm{Mn}, \mathrm{Al})$ by powder microelectrode technique, International Journal of Hydrogen Energy 32 (12) (2007) 1905-1910.

[36] C. Y. V. Li, Z. M. Wang, S. Liu, S. L. I. Chan, Electrochemical characteristics of La-Ni-Al thin films, Journal of Alloys and Compounds 456 (1-2) (2008) 407-412.

[37] Z.-P. Li, Y.-Q. Lei, C.-P. Chen, J. Wu, Q.-D. Wang, The relation between discharge capacities and discharge current densities of hydride electrodes, Journal of the Less Common Metals 172 (1991) 1260-1264.

[38] A. Saidi, L. Desfontaines, A. Champeval, J.-D. Lebreux, C. Lecomte, M. Pruneau, A. Grondein, R. Izquierdo, D. Bélanger, The effect of ink formulation and electrode geometry design on the electrochemical performance of a printed alkaline battery, Flexible and Printed Electronics 2 (1) (2017) 015002.

[39] T. Sakai, H. Ishikawa, K. Oguro, C. Iwakura, H. Yoneyama, Effects of microencapsulation of hydrogen storage alloy on the performances of sealed nickel/metal hydride batteries, Journal of The Electrochemical Society 134 (3) (1987) 558-562.

[40] Y. Fukumoto, M. Miyamoto, M. Matsuoka, C. Iwakura, Effect of the stoichiometric ratio on electrochemical properties of hydrogen storage 
alloys for nickel-metal hydride batteries, Electrochimica Acta 40 (7) (1995) 845-848.

[41] J. F. Oudenhoven, L. Baggetto, P. H. Notten, All-solid-state lithiumion microbatteries: a review of various three-dimensional concepts, Advanced Energy Materials 1 (1) (2011) 10-33.

[42] H.-S. Min, B. Y. Park, L. Taherabadi, C. Wang, Y. Yeh, R. Zaouk, M. J. Madou, B. Dunn, Fabrication and properties of a carbon/polypyrrole three-dimensional microbattery, Journal of Power Sources 178 (2) (2008) 795-800.

[43] P. H. Humble, J. N. Harb, R. LaFollette, Microscopic nickel-zinc batteries for use in autonomous microsystems, Journal of the Electrochemical Society 148 (12) (2001) A1357-A1361.

[44] P. H. Humble, J. N. Harb, Optimization of nickel-zinc microbatteries for hybrid powered microsensor systems, Journal of the Electrochemical Society 150 (9) (2003) A1182-A1187.

[45] J. Xu, Y. Li, F. Wang, Effect of al content on the electrochemical properties of $\mathrm{Mg}_{2-x} \mathrm{Al}_{x} \mathrm{Ni}$ thin film hydride electrodes, Electrochimica Acta 55 (1) (2009) 148-154.

[46] B. Zhang, W. Wu, X. Bian, G. Tu, Investigations on rate constants of the charging/discharging processes for metal hydride electrodes, Electrochimica Acta 87 (2013) 645-650.

[47] P. Slepski, K. Darowicki, E. Janicka, A. Sierczynska, Application of electrochemical impedance spectroscopy to monitoring discharging process 
of nickel/metal hydride battery, Journal of Power Sources 241 (2013) 121-126. 